\title{
Liquid-crystalline main-chain polymers with a poly(p- phenylene terephthalate) backbone. 1. Synthesis, characterization and rheology of polyesters with alkoxy side chains
}

Citation for published version (APA):

Damman, S. B., Mercx, F. P. M., \& Kootwijk-Damman, C. M. (1993). Liquid-crystalline main-chain polymers with a poly(p-phenylene terephthalate) backbone. 1. Synthesis, characterization and rheology of polyesters with alkoxy side chains. Polymer, 34(9), 1891-1897. https://doi.org/10.1016/0032-3861(93)90431-9

DOI:

10.1016/0032-3861(93)90431-9

Document status and date:

Published: 01/01/1993

Document Version:

Publisher's PDF, also known as Version of Record (includes final page, issue and volume numbers)

Please check the document version of this publication:

- A submitted manuscript is the version of the article upon submission and before peer-review. There can be important differences between the submitted version and the official published version of record. People interested in the research are advised to contact the author for the final version of the publication, or visit the $\mathrm{DOI}$ to the publisher's website.

- The final author version and the galley proof are versions of the publication after peer review.

- The final published version features the final layout of the paper including the volume, issue and page numbers.

Link to publication

\footnotetext{
General rights

- You may freely distribute the URL identifying the publication in the public portal. follow below link for the End User Agreement:

www.tue.nl/taverne

Take down policy

If you believe that this document breaches copyright please contact us at:

openaccess@tue.nl

providing details and we will investigate your claim.
}

Copyright and moral rights for the publications made accessible in the public portal are retained by the authors and/or other copyright owners and it is a condition of accessing publications that users recognise and abide by the legal requirements associated with these rights.

- Users may download and print one copy of any publication from the public portal for the purpose of private study or research.

- You may not further distribute the material or use it for any profit-making activity or commercial gain

If the publication is distributed under the terms of Article $25 \mathrm{fa}$ of the Dutch Copyright Act, indicated by the "Taverne" license above, please 


\title{
Liquid-crystalline main-chain polymers with a poly ( $p$-phenylene terephthalate) backbone: 1. Synthesis, characterization and rheology of polyesters with alkoxy side chains
}

\author{
S. B. Damman* and F. P. M. Mercx \\ TNO Plastics and Rubber Research Institute, PO Box 6031, 2600 JA Delft, The Netherlands \\ and C. M. Kootwijk-Damman \\ Eindhoven University of Technology, Centre for Polymers and Composites, PO Box 513, \\ $5600 \mathrm{MB}$ Eindhoven, The Netherlands
}

(Received 26 May 1992)

\begin{abstract}
The influence of the position and length of alkoxy substitutents on the phase behaviour of poly( $p$-phenylene terephthalate)s was investigated by differential scanning calorimetry and rheological measurements. The two polymers with respectively dodecyloxy and hexyloxy side chains on the terephthalate moiety (PTA12HQ and PTA6HQ) both showed stable liquid-crystalline phases. For these two polymers the location of the transition temperatures as a function of the molecular weight (inherent viscosity) was shown to level off above an inherent viscosity of $2 \mathrm{dl} \mathrm{g}^{-1}$. From rheological measurements it is concluded that the layered mesophase, shown by PTA6HQ and PTA12HQ, behaves more like a solid than a liquid. For the nematic mesophase, only shown by PTA6HQ, a minimum in the viscosity-temperature curve was found. The polymer with dodecyloxy substituents on the hydroquinone moiety (PTAHQ12) only shows mesomorphic behaviour on cooling, while the polymer with double the amount of substituents (PTA12HQ12) does not show any liquid-crystalline behaviour.
\end{abstract}

(Keywords: rigid-rod polymer; thermotropic; synthesis; phase behaviour; rheology; poly(p-phenylene terephthalate))

\section{INTRODUCTION}

Rigid-rod polymers form a separate class of polymers because of their ability to form a liquid-crystalline phase. This creates the possibility to form highly oriented structures in a simple way. A typical example is poly ( $p$-phenylene terephthalamide), from which the highmodulus, high-strength Twaron (Akzo) and Kevlar (Du Pont) fibres are spun. This polymer is unmeltable and can only be spun from a sulphuric acid solution ${ }^{1}$.

Obviously the development of melt-processable liquidcrystalline polymers (LCPs) has received a great deal of attention over the past years. Melt processability can be obtained in several ways ${ }^{2}$. A well known method is to disrupt the regular structure of the main chain by random copolymerization and/or the introduction of 'crankshafts' in the chain. Both methods are employed in the Vectra (Hoechst-Celanese) polymer. It results in a frustrated chain packing in the solid state, thus lowering the melting point. In another approach the chain stiffness is lowered to obtain a meltable LCP (poly(ethylene terephthalate) (PET)) modified with rigid $p$-hydroxybenzoic acid (pHBA) units, also known as $\mathrm{X} 7 \mathrm{G}$ from Eastman-Kodak).

\footnotetext{
* To whom correspondence should be addressed
}

However, a decrease in chain stiffness will eventually lead to a loss of the ability to form liquid-crystalline phases.

Though there has been considerable progress in studying the structure and properties of these polymers, full understanding is hampered by some inherent disadvantages. Especially in the case of random copolymers the unknown and probably unstable (due to transesterification) sequence distribution of the building units $^{3}$ gives rise to a complicated solid-state behaviour ${ }^{4,5}$. Furthermore the insolubility in common organic solvents obstructs easy characterization on a molecular level.

The difficulties encountered in investigating the abovementioned systems emphasize the need for additional research on LCPs of non-random copolymeric nature. Thus the polymers described in this study are based on a rigid poly(p-phenylene terephthalate) backbone (abbreviated as PPT). In order to obtain meltability (and solubility), flexible aliphatic side chains are attached to this backbone. Following the abbreviations used by Rodriguez-Parada ${ }^{6}$ the resulting polymers are designated as PTAnHQ, PTAHQn and PTAnHQn (Scheme I).

The flexible side chains will act as a 'bonded solvent' and thus create a meltable polymer. From a practical ${ }^{7}$ as well as a theoretical ${ }^{8}$ point of view, it is well known that increasing the amount of substitution and/or the 


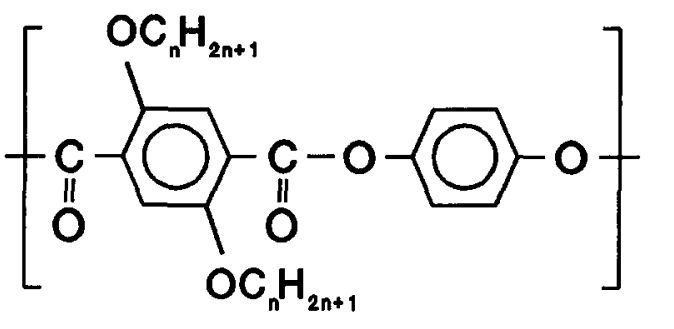

PTAnHQ $n=6,12$

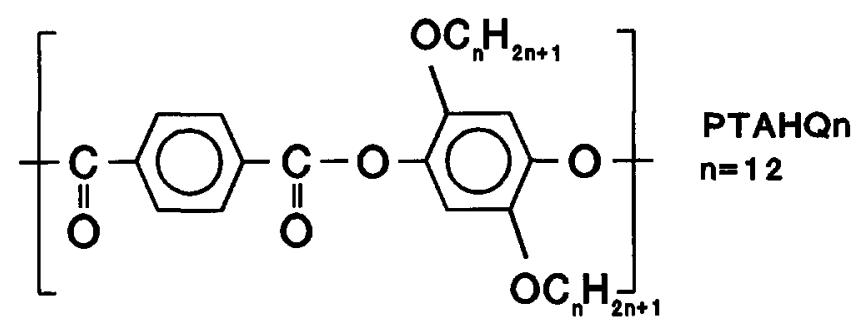

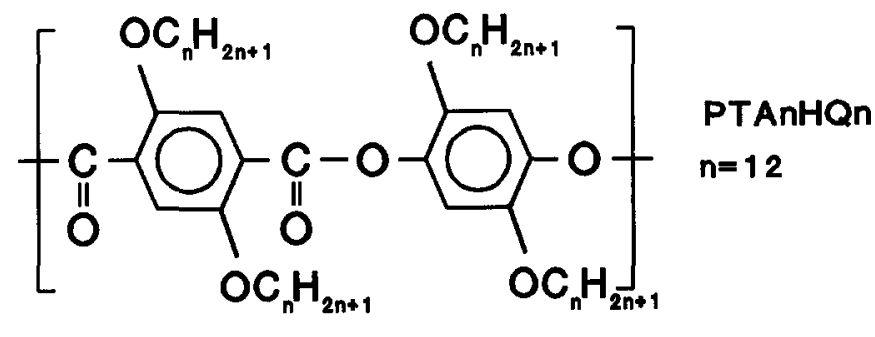

Scheme 1

length of the side chains will result in a lower melting point.

For PTAnHQ it is known that a layered mesophase can be formed when the side chains exceed a certain length ${ }^{9,10}$. In this layered mesophase the side chains interdigitate and the main chains form layers (see Figure 1). The distance between these layers is proportional to the length of the side chains, and increases by $1.25 \AA$ for each added $\mathrm{CH}_{2}$ unit $^{9,10}$. At room temperature two crystal modifications $A$ and $B$ are found in which the characteristic layer distance increases by 1.25 and $0.82 \AA$ per $\mathrm{CH}_{2}$ unit respectively ${ }^{10}$.

For PTAnHQ polymers with long side chains $(n \geqslant 12)$ three disordering transitions can be seen upon heating both modifications. These transitions are associated with the side chains, the main chains (formation of the layered mesophase) and the transformation to the isotropic melt. For a polymer with shorter side chains a nematic mesophase is observed in addition ${ }^{9,11}$.

For PTA12HQn and PTA16HQn it was shown by Rodriguez-Parada et al. ${ }^{6}$ that the phase behaviour of these alkoxy-substituted polymers is significantly affected by the position and length of substituents.

The rheology of a PTAnHQ polymer with short side chains, PTA6HQ, as well as that of a polymer with long side chains, PTA16HQ, has been described recently by Schrauwen et al. ${ }^{12}$. They concluded that, above the isotropization temperature, PTA16HQ behaves like a conventional polymer in the melt. For PTA6HQ with a fairly low molecular weight $\left([\eta]=0.48 \mathrm{dl} \mathrm{g}^{-1}\right)$ they observed the flow-thinning effect typical of liquidcrystalline polymers.

In this paper two polymers with alkoxy substituents of different lengths on the terephthalate moiety, PTA6HQ and PTA12HQ, will be compared with regard to their phase behaviour. As the molecular weight is known to have a significant influence on the transition temperature of most polymers, this dependence will be investigated as well.

The influence of the position and amount of the substituents on the phase behaviour will be investigated by attaching dodecyloxy side chains on the hydroquinone moiety alone (PTAHQ12), or on both moieties (PTA12HQ12). To gain further insight into the rheological behaviour of the layered mesophase displayed by PTA6HQ and PTA12HQ, as well as the nematic mesophase shown by PTA6HQ, rheological measurements will be performed. Comparisons between the rheological behaviour of these two liquid-crystalline polymers with the two other polymers, PTAHQ12 and PTA12HQ12, will be made.

The complex relations between molecular structure, crystal structure, phase behaviour, processing, relaxation behaviour (dynamic mechanical as well as dielectric) and ultimate mechanical properties of these polymers will be dealt with in detail in following publications.

\section{EXPERIMENTAL}

\section{Materials}

Diethyl 2,5-dihydroxyterephthalate (Riedel-de Haen, 98\%), 1-bromododecane (Aldrich, 98\%), 1-bromohexane (Janssen Chimica, >99\%), 2,5-dihydroxybenzoquinone (Aldrich, 98\%), 1-dodecanol (Aldrich, 98\%), sodium dithionite (Aldrich) as well as acetone (Merck, P.A. quality) were used without further purification. Hydroquinone (Merck, Zur Synthese) was purified by sublimation in vacuo. Thionyl chloride (Fluka, $>99 \%$ ), pyridine (Merck, P.A.), as well as 1,1,2,2-tetrachloroethane (Merck, Zur Synthese) were distilled in vacuo prior to use.

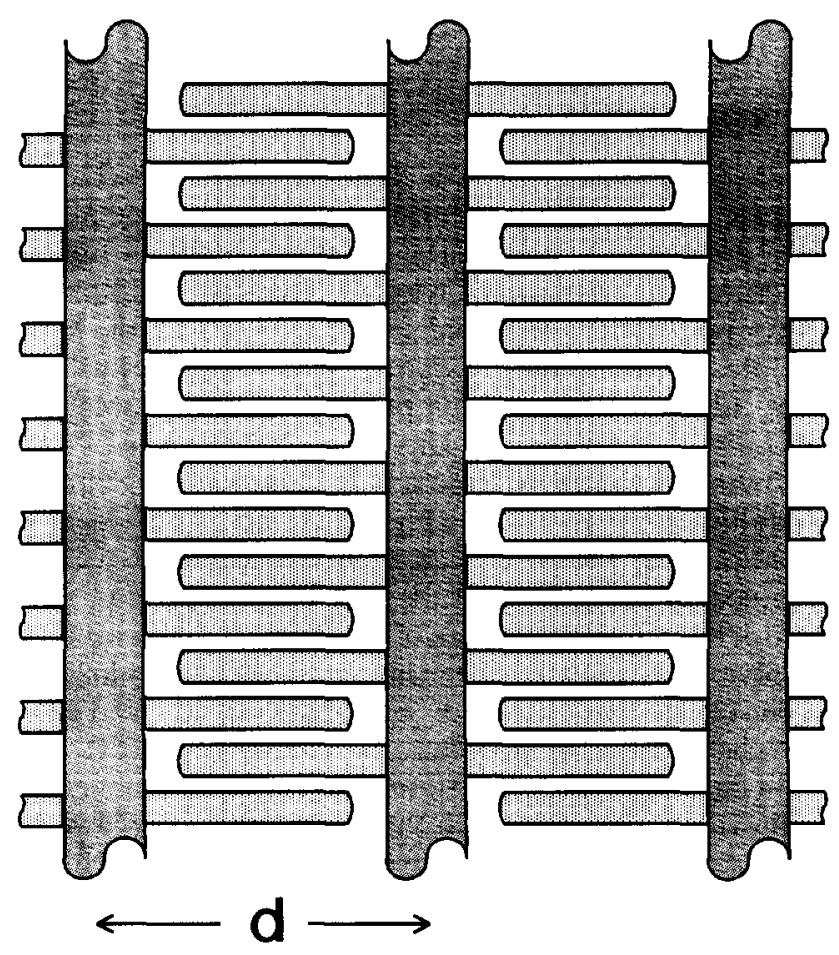

Figure 1 Schematic representation of the layered mesophase; the main chains are separated by the interdigitating side chains at the layer distance $d$ (after Ballauff ${ }^{10}$ ) 


\section{Synthesis of monomers}

2,5-Dialkoxyterephthaloyl chlorides were synthesized from diethyl 2,5-dihydroxyterephthalate in three steps by a similar, but slightly modified, procedure as described earlier by Ballauff 7 . In the first step $152.5 \mathrm{~g}(0.6 \mathrm{~mol})$ of diethyl 2,5-dihydroxyterephthalate, $165.8 \mathrm{~g}(1.2 \mathrm{~mol})$ of potassium carbonate and $3.0 \mathrm{~mol}$ of 1 -bromoalkane were refluxed in 3.6 litres of acetone until the yellow-orange colour had disappeared. After nearly complete reaction, as indicated by ${ }^{1} \mathrm{H}$ n.m.r., the solid potassium bromide was filtered off and the acetone was removed in vacuo. The resulting alkoxy-substituted diethyl terephthalate was recrystallized twice from ethanol.

Diethyl 2,5-didodecyloxyterephthalate. Yield 78\%; m.p. 62-64 ${ }^{\circ} \mathrm{C}$ (lit. ${ }^{7}$ m.p. $57^{\circ} \mathrm{C}$ ). \% 73.36 (calcd. 73.18 ), \% $\mathrm{H}$ 10.64 (calcd. 10.58). ${ }^{1} \mathrm{H}$ n.m.r. (acetone- $\mathrm{d}_{6}$ ): $\delta=4.32$ (q, $\left.\mathrm{OCH}_{2} \mathrm{CH}_{3}\right), 1.35\left(\mathrm{t}, \mathrm{OCH}_{2} \mathrm{CH}_{3}, J=7.1 \mathrm{~Hz}\right), 7.33(\mathrm{~s}$, $\mathrm{H}(\mathrm{Ar})), 4.03\left(\mathrm{t}, \mathrm{OCH}_{2} \mathrm{C}_{11} \mathrm{H}_{23}\right), 1 . \overline{78}\left(\mathrm{~m}, \mathrm{OCH}_{2} \mathrm{CH}_{2} \mathrm{C}_{10} \mathrm{H}_{21}\right)$, $1.52\left(\mathrm{~m}, \mathrm{OC}_{2} \mathrm{H}_{4} \overline{\mathrm{CH}}_{2} \mathrm{C}_{9} \mathrm{H}_{19}\right), 1.25-1.42\left(\mathrm{~m}, \overline{\mathrm{OC}}_{3} \mathrm{H}_{6} \mathrm{C}_{8^{-}}\right.$ $\left.\underline{\mathrm{H}}_{16} \mathrm{CH}_{3}\right), 0.88 \mathrm{ppm}\left(\mathrm{t}, \mathrm{OC}_{11} \mathrm{H}_{22} \mathrm{CH}_{3}\right)$.

Diethyl 2,5-dihexyloxyterephthalate. Yield 79\%; m.p. $41-43^{\circ} \mathrm{C}$ (lit. ${ }^{7}$ m.p. $39^{\circ} \mathrm{C}$ ). $\% \mathrm{C} 68.20$ (calcd. 68.22 ), $\% \mathrm{H}$ 8.69 (calcd. 9.06). ${ }^{1} \mathrm{H}$ n.m.r. (DMSO-d ${ }_{6}$ ): $\delta=4.27$ (q, $\left.\mathrm{OCH}_{2} \mathrm{CH}_{3}\right), 1.30\left(\mathrm{t}, \mathrm{OCH}_{2} \mathrm{CH}_{3}, J=7.0 \mathrm{~Hz}\right), 7.28$ (s, $\mathrm{H}(\overline{\mathrm{Ar}})), 3.97\left(\mathrm{t}, \mathrm{OCH}_{2} \mathrm{C}_{5} \mathrm{H}_{11}\right), 1.67\left(\mathrm{~m}, \mathrm{OCH}_{2} \mathrm{CH}_{2} \mathrm{C}_{4} \mathrm{H}_{9}\right)$, $1.42\left(\mathrm{~m}, \mathrm{OC}_{2} \mathrm{H}_{4} \overline{\mathrm{CH}}_{2} \mathrm{C}_{3} \mathrm{H}_{7}\right), 1.26-1.32\left(\mathrm{~m}, \mathrm{OC}_{3} \mathrm{H}_{7} \mathrm{C}_{2}-\right.$ $\left.\mathrm{H}_{4} \mathrm{CH}_{3}\right), 0.87 \mathrm{ppm}\left(\mathrm{t}, \mathrm{OC}_{5} \mathrm{H}_{10} \mathrm{CH}_{3}\right)$.

The acids were obtained from the esters as explained in the following example. A solution of $200.8 \mathrm{~g}(0.475 \mathrm{~mol})$ of diethyl 2,5-dihexyloxyterephthalate in 0.5 litres of ethanol was treated, under reflux conditions, with a solution of $266.8 \mathrm{~g}(4.76 \mathrm{~mol})$ potassium hydroxide in 0.62 litres of water ( $30 \mathrm{wt} \%$ aqueous solution, 10 -fold amount of excess) for approximately $45 \mathrm{~min}$. In order to maintain a clear solution, $150 \mathrm{ml}$ of ethanol was added, and reflux was continued, under vigorous stirring, for $3-4 \mathrm{~h}$. After cooling to $0^{\circ} \mathrm{C}$, the solution was neutralized with a small excess of concentrated $\mathrm{HCl}$ from which the acid precipitated. Recrystallization from a mixture of ethanol $/ \mathrm{H}_{2} \mathrm{O}(4 / 1, \mathrm{v} / \mathrm{v})$ afforded white needles in nearly quantitative yield.

2,5-Didodecyloxyterephthalic acid. Yield 96\%; m.p. $136-138^{\circ} \mathrm{C}$ (lit. ${ }^{7}$ m.p. $128^{\circ} \mathrm{C}$ ). $\% \mathrm{C} 71.73$ (calcd. 71.87 ), $\% \mathrm{H} 10.16$ (calcd. 10.18).

2,5-Dihexyloxyterephthalic acid. Yield 92\%; m.p. $144-146^{\circ} \mathrm{C}$ (lit. $^{7}$ m.p. $138^{\circ} \mathrm{C}$ ). $\% \mathrm{C} 65.56$ (calcd. 65.55), $\%$ H 8.05 (calcd. 8.25). ${ }^{1} \mathrm{H}$ n.m.r. (DMSO-d $\mathrm{d}_{6}$ ): $\delta=12.85$ (s, $\mathrm{COOH}$ ), 7.27 (s, $\mathrm{H}(\mathrm{Ar})$ ), 3.98 (t, $\mathrm{OCH}_{2} \mathrm{C}_{5} \mathrm{H}_{11}$ ), 1.68 $\left(\mathrm{m}, \mathrm{OCH}_{2} \mathrm{CH}_{2} \mathrm{C}_{4} \mathrm{H}_{9}\right), 1.42\left(\mathrm{~m}, \mathrm{OC}_{2} \mathrm{H}_{4} \mathrm{CH}_{2} \overline{\mathrm{C}}_{3} \mathrm{H}_{7}\right), 1.26-1.32$ $\left(\mathrm{m}, \mathrm{OC}_{3} \mathrm{H}_{7} \overline{\mathrm{C}}_{2} \underline{\mathrm{H}}_{4} \mathrm{CH}_{3}\right), 0.87 \mathrm{ppm}\left(\mathrm{t}, \mathrm{OC}_{5} \mathrm{H}_{10} \underline{\mathrm{CH}}_{3}\right)$.

In the third and last step the acid was refluxed with a 10-fold excess of thionyl chloride for approximately $4 \mathrm{~h}$. To avoid contact with air the excess of thionyl chloride was removed by distillation, and the acid chloride was isolated from the crude product by extraction with $\mathrm{n}$-hexane in a Soxhlet apparatus, followed by crystallization from the same solvent.

2,5-Didodecyloxyterephthalic acid chloride. Yield 88\%; m.p. $69-71^{\circ} \mathrm{C}$ (lit. ${ }^{7}$ m.p. $60^{\circ} \mathrm{C}$ ). $\% \mathrm{C} 67.65$ (calcd. 67.23), $\% \mathrm{H} 9.06$ (calcd. 9.17), \%Cl 12.41 (calcd. 12.40).

2,5-Dihexyloxyterephthalic acid chloride. Yield 92\%; m.p. $37-39^{\circ} \mathrm{C}$ (lit. ${ }^{7} \mathrm{~m} . \mathrm{p} .63^{\circ} \mathrm{C}$, apparently a printing error). \%C 59.79 (calcd. 59.56), \%H 7.06 (calcd. 7.00), \% Cl 17.38 (calcd. 17.58).
The dodecyloxy-substituted hydroquinone was prepared from 2,5-dihydroxybenzoquinone in two steps following modified literature procedures ${ }^{13,14}$. In the first step $15 \mathrm{~g}$ $(0.41 \mathrm{~mol})$ dry $\mathrm{HCl}$ gas was passed into $800 \mathrm{ml}(3.56 \mathrm{~mol})$ dodecanol at $50^{\circ} \mathrm{C}^{13}$. To this solution $17.0 \mathrm{~g}(0.12 \mathrm{~mol})$ of dihydroxybenzoquinone was added and a highly viscous and turbid solution was formed. The temperature of the solution was raised to $100^{\circ} \mathrm{C}$ and maintained at this temperature for $3 \mathrm{~h}$, while continuously stirring. By then the solution had turned clear dark-brown and was cooled to room temperature. Approximately 1.5 litres of ether was added to the cooled solution and the yellow product was filtered off and washed twice with ether. After recrystallization from ethanol, yellow crystals of 2,5-didodecyloxy- $p$-benzoquinone were obtained.

2,5-Didodecyloxy-p-benzoquinone. Yield $60 \%$; m.p. $125-126^{\circ} \mathrm{C}$ (lit. ${ }^{6} 124^{\circ} \mathrm{C}$ ). ${ }^{1} \mathrm{H}$ n.m.r. $\left(\mathrm{CDCl}_{3}\right): \delta=5.71$ (s, $\mathrm{H}(\mathrm{Ar})), 3.81\left(\mathrm{t}, \mathrm{OCH}_{2} \mathrm{C}_{11} \mathrm{H}_{25}\right), 1.73\left(\mathrm{~m}, \mathrm{OCH}_{2} \mathrm{CH}_{2} \mathrm{C}_{10} \mathrm{H}_{21}\right)$, $1.31\left(\mathrm{~m}, \mathrm{OC}_{2} \mathrm{H}_{4} \mathrm{CH}_{2} \mathrm{C}_{9} \mathrm{H}_{19}\right), 1.15-1.21\left(\mathrm{~m}, \mathrm{OC}_{3} \mathrm{H}_{6} \mathrm{C}_{8} \mathrm{H}_{16}\right.$ $\left.\mathrm{CH}_{3}\right), 0.77 \mathrm{ppm}\left(\mathrm{t}, \mathrm{OC}_{11} \mathrm{H}_{22} \mathrm{CH}_{3}\right)$.

In the second step ${ }^{14} 26.7 \mathrm{~g}(0.056 \mathrm{~mol})$ of 2,5-dodecyloxysubstituted benzoquinone was dissolved in $600 \mathrm{ml}$ chloroform and mixed with a solution of $191 \mathrm{~g}(1 \mathrm{~mol})$ $\mathrm{Na}_{2} \mathrm{~S}_{2} \mathrm{O}_{4}$ in $1000 \mathrm{ml}$ water. After stirring for $20 \mathrm{~h}$ the red-yellow colour of the solution had disappeared and the 2,5-didodecyloxyhydroquinone precipitated. This product was recrystallized from hexane and was obtained as white needles.

2,5-Didodecyloxyhydroquinone. Yield $82 \%$; m.p. $104.7^{\circ} \mathrm{C}$ (lit. ${ }^{6} 102.5^{\circ} \mathrm{C}$ ). ${ }^{1} \mathrm{H}$ n.m.r. (DMSO-d ${ }_{6}$ ): $\delta=6.40$ (s, H(Ar)), $3.82\left(\mathrm{t}, \mathrm{OCH}_{2} \mathrm{C}_{11} \mathrm{H}_{25}\right), 1.65\left(\mathrm{~m}, \mathrm{OCH}_{2} \mathrm{CH}_{2} \mathrm{C}_{10} \mathrm{H}_{21}\right), 1.39$ $\left(\mathrm{m}, \mathrm{OC}_{2} \mathrm{H}_{4} \overline{\mathrm{CH}}_{2} \mathrm{C}_{9} \mathrm{H}_{19}\right), 1.35-1.25\left(\mathrm{~m}, \mathrm{OC}_{3} \mathrm{H}_{6} \mathrm{C}_{8} \mathrm{H}_{16} \mathrm{CH}_{3}\right.$ ), $0.86 \mathrm{ppm}\left(\mathrm{t}, \overline{\mathrm{OC}}_{11} \mathrm{H}_{22} \mathrm{CH}_{3}\right)$.

\section{Polymerization}

Polymers were synthesized by polycondensation in solution. In a typical example $39.49 \mathrm{~g}(97.9 \mathrm{mmol})$ of 2,5-dihexyloxyterephthalic acid chloride and an equivalent amount of hydroquinone $(10.78 \mathrm{~g})$ were added to $290 \mathrm{ml}$ of 1,1,2,2-tetrachloroethane, which was already present in a three-necked flask fitted with a dropping funnel, a nitrogen inlet and a stirring unit. The resulting mixture was heated to obtain a homogeneous solution, cooled to room temperature - a small part of the hydroquinone did not dissolve - and a four-fold excess of pyridine $(25 \mathrm{ml})$ was slowly added over $20 \mathrm{~min}$. After the pyridine had been added completely, stirring of the highly viscous and turbid solution was continued for approximately $3 \mathrm{~h}$ to complete the reaction. The solution was diluted with approximately twice the volume of solvent and poured into a seven-fold volume excess of methanol (ca. 3.5 litres). The polymer precipitated, and was filtered, washed with methanol and dried to constant weight in vacuo at $60^{\circ} \mathrm{C}$. Yield was nearly quantitative.

It is worth noting that, in the polymerization process in which the 2,5-didodecyloxy-substituted hydroquinone is one of the monomers, the solution turns red when the pyridine is added. This is probably caused by the formation of a charge-transfer complex and was also noted by others during melt polymerization ${ }^{6}$. After a short while, when the polymerization reaction has actually started, the solution becomes yellow.

The inherent viscosities of the synthesized polymers were between 0.94 and $3.32 \mathrm{dl} \mathrm{g}^{-1}$ for PTA12HQ and between 1.61 and $2.33 \mathrm{dl} \mathrm{g}^{-1}$ for PTA6HQ. For 
PTAHQ12 and PTA12HQ12 inherent viscosities of 0.70 and $1.39 \mathrm{dl} \mathrm{g}^{-1}$ were obtained.

\section{Characterization methods}

D.s.c. measurements were performed on a DuPont 9900 DSC and on a Perkin-Elmer DSC7. The heating rate was $20^{\circ} \mathrm{C} \mathrm{min}-1$. The peak of the melting endotherm was taken as the melting point.

N.m.r. spectra were recorded at $30^{\circ} \mathrm{C}$ on a Varian VXR400 spectrometer $\left({ }^{1} \mathrm{H}\right.$ resonance frequency $\left.400 \mathrm{MHz}\right)$ using a $5 \mathrm{~mm}$ switchable probe and a VXR data system. Tetramethylsilane (TMS) was used as internal reference for the proton spectra.

Inherent viscosities were determined at $25^{\circ} \mathrm{C}$ with solutions of the polymers in $\mathrm{CHCl}_{3}\left(2 \mathrm{gl}^{-1}\right)$ using an Ubbelohde capillary viscosimeter.

Dynamic rheological measurements were performed on a Rheometrics RDS-2 mechanical spectrometer in the parallel-plate arrangement using $25 \mathrm{~mm}$ plates. The parallel-plate gap spacing was $1-1.5 \mathrm{~mm}$ and the dynamic strain amplitude was $1 \%$. Samples were prepared on a press by compressing dried powders to $25 \mathrm{~mm}$ diameter plaques at $50^{\circ} \mathrm{C}$ (PTAHQ12), $190^{\circ} \mathrm{C}$ (PTA12HQ12) and $260^{\circ} \mathrm{C}$ (PTA6HQ, PTA12HQ). The rheological measurements were performed under a nitrogen atmosphere. As checked by g.p.c. no significant sample degradation occurred.

\section{RESULTS AND DISCUSSION}

\section{Thermal behaviour}

In Figure 2 the d.s.c. thermograms of the four polymers are shown. In agreement with observations made by others ${ }^{6,7,10}$ the existence of a glass transition could not be determined unambiguously by this technique for any of the polymers.

PTA12HQ shows three endotherms, which are denoted as $T_{\mathrm{s}}, T_{\mathrm{m}}$ and $T_{\mathrm{i}}$ (see Table 1 and Figure 2). The first-order transition at the lowest temperature, $T_{\mathrm{s}}$, is caused by a disordering of the side chains. At this temperature conformational and positional order of the side chains decreases ${ }^{10,15}$. In the first heating run it is located at $108^{\circ} \mathrm{C}\left(\Delta H \approx 50 \mathrm{~J} \mathrm{~g}^{-1}\right)$ and in the second heating run at $38^{\circ} \mathrm{C}\left(\Delta H \approx 15 \mathrm{~J} \mathrm{~g}^{-1}\right)$. This difference is caused by a change in crystal structure; solution-precipitated powder is in crystal form $B$, while once molten powder is in crystal form $A^{10}$. Irrespecitve of the polymer's initial crystal form the polymer is in the less ordered structure $\mathrm{A}^{\prime}$ above the side-chain disordering temperature $T_{\mathrm{s}}$ (ref. 16). The endotherm at $T_{\mathrm{m}}$ has been ascribed to the transition to the layered mesophase, $L_{m}$ (ref. 10). Above this

Table 1 Transition temperatures (first/second heating runs) of the d.s.c. thermograms shown in Figure 2

\begin{tabular}{llllll}
\hline Polymer & $\eta_{\text {inh }}\left(\mathrm{dl} \mathrm{g}^{-1}\right)$ & $T_{\mathrm{s}}\left({ }^{\circ} \mathrm{C}\right)^{a}$ & $T_{\mathrm{m}}\left({ }^{\circ} \mathrm{C}\right)^{b}$ & $T_{\mathrm{n}}\left({ }^{\circ} \mathrm{C}\right)^{c}$ & $T_{\mathrm{i}}\left({ }^{\circ} \mathrm{C}\right)^{d}$ \\
\hline PTA12HQ & 2.3 & $108 / 38$ & $161 / 175$ & - & $243 / 243$ \\
PTA6HQ & 2.3 & - & $183 / 177$ & $233 / 221$ & $286 / 282$ \\
PTAHQ12 & $0.7^{e}$ & $118 / 80$ & - & - & $239 / 242$ \\
PTA12HQ12 & 1.4 & $82 / 87$ & - & - & $189 / 188$
\end{tabular}

${ }^{a}$ Side-chain disordering temperature

${ }^{b}$ Main-chain melting temperature, formation of layered mesophase

'Transition temperature from layered mesophase to nematic mesophase

${ }^{d}$ Transition temperature to isotropic melt

- Measured in p-chlorophenol at $50^{\circ} \mathrm{C}$
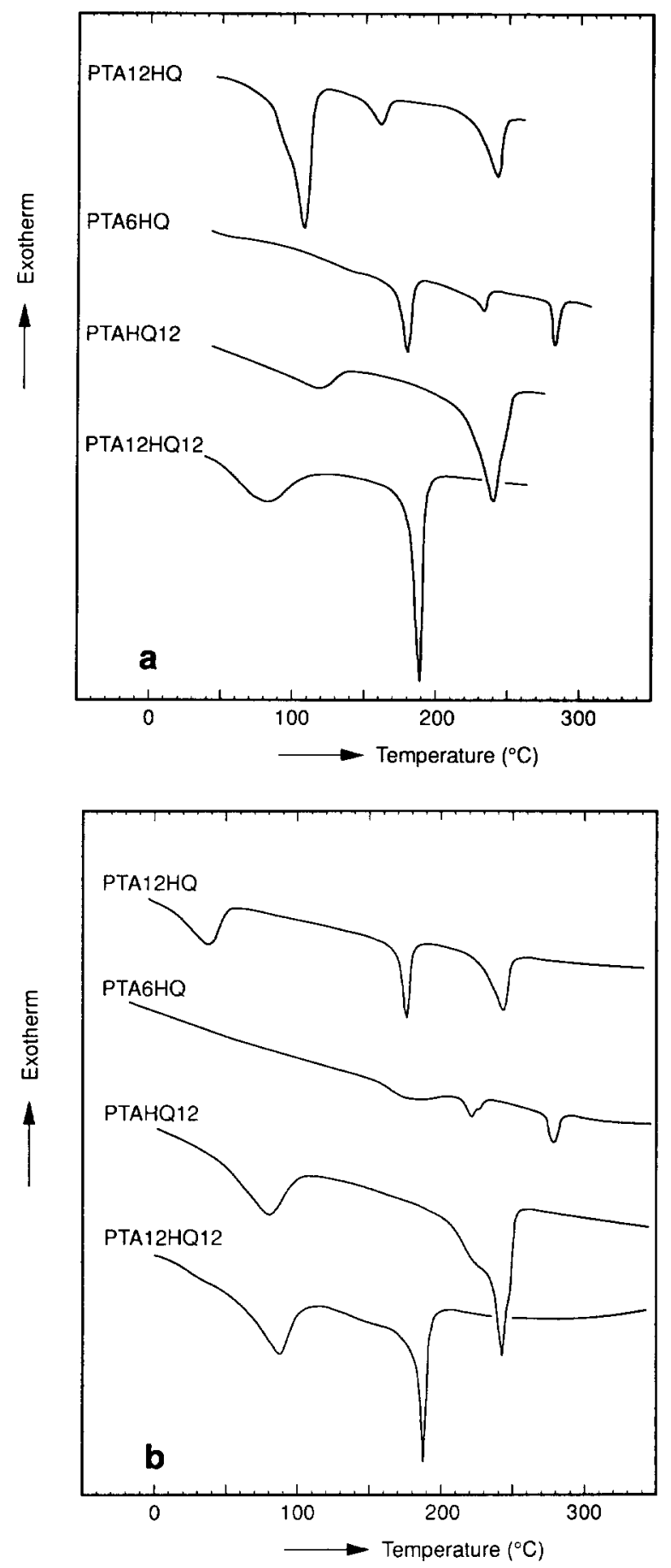

Figure 2 D.s.c. thermograms of the PTA12HQ, PTA6HQ, PTAHQ12 and PTA12HQ12 powders: (a) first heating run, (b) second heating run

temperature the main chains are still aligned parallel in a layered structure, but their position/distance relative to each other is not well defined. The layer distance $d$ in phase $L_{m}$ has a value comparable to that of modification $\mathrm{A}^{10}$. Throughout this paper this temperature will be referred to as the main-chain melting temperature. The lower value of $T_{\mathrm{m}}$ in the first heating run (compared to the second heating run) may be explained by slight differences in the structure of phase $A^{\prime}$ in first and second heating runs. Eventually the parallel ordering of the main chains is lost at the clearing temperature $T_{\mathrm{i}}$ and an isotropic phase is formed. The phase behaviour of PTA12HQ is shown schematically in Figure 3.

Several batches of PTA12HQ were synthesized and 


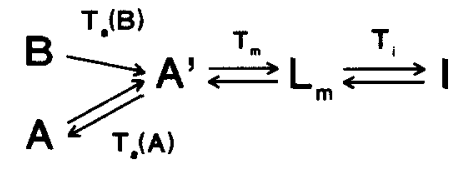

Figure 3 Scheme of the phase behaviour in PTA12HQ powders, showing the transitions from the two room-temperature modifications $A$ and $B$ to the intermediate phase $A^{\prime}$, the layered mesophase $L_{m}$ and the isotropic phase I. Note that B is only available in the as-made powder; this modification cannot be obtained by cooling from the melt

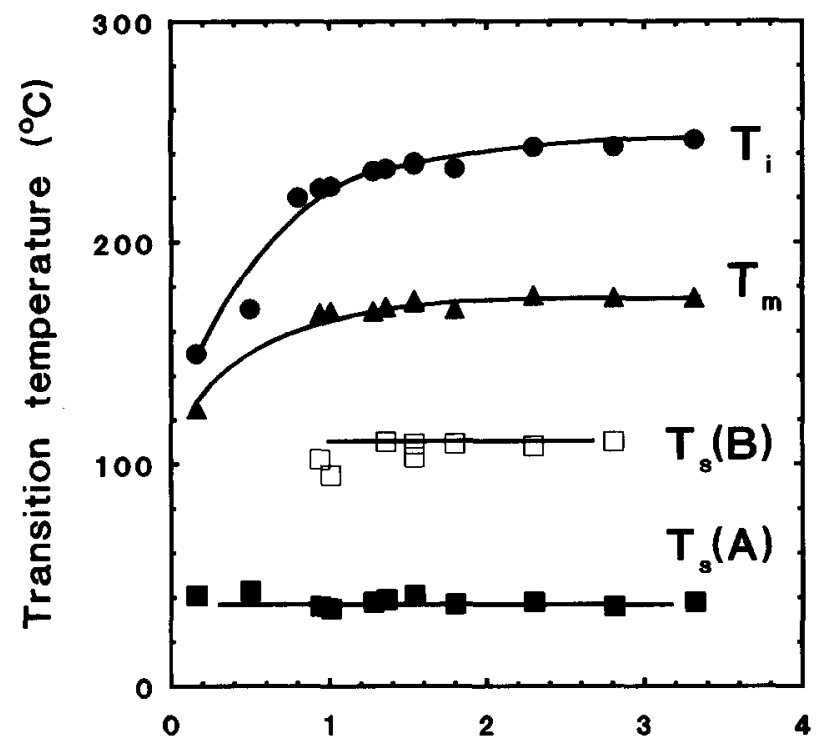

Inherent viscosity (dl/g)

Figure 4 Transition temperatures $T_{\mathrm{s}}(\mathrm{A})(\mathbf{D}), T_{\mathrm{m}}(\mathbf{A})$ and $T_{\mathrm{i}}(\mathbf{O})$ (all from the second heating runs) and $T_{s}(B)(\square)$ (from the first heating run) as functions of the inherent viscosity for PTA12HQ. Data below $\eta_{\text {inh }}=0.6 \mathrm{dl} \mathrm{g}^{-1}$ were taken from Ballauff ${ }^{7}$

the effect of the molecular weight on the transition temperatures is shown in Figure 4. The side-chain disordering temperature of both modifications $A$ and $B$ remains almost constant for all molecular weights. The main-chain melting and especially the clearing temperature show a considerable molecular-weight dependence; the region between $T_{\mathrm{m}}$ and $T_{\mathrm{i}}$, in which the liquid-crystalline phase exists, extends with molecular weight. Similar to the poly(2-n-alkyl-1,4-phenylene terephthalate)s described by Majnusz et $a l^{17,18}$, the molecular-weight dependence is very strong below an inherent viscosity of $1 \mathrm{dl} \mathrm{g}^{-1}$. Above this value a small, continuous increase in transition temperatures exists, which starts to level off at an inherent viscosity of $2 \mathrm{dl} \mathrm{g}^{-1}$.

In the d.s.c. thermograms of the polymer with hexyloxy side chains, PTA6HQ, no separate disordering transition of the side chains is observed (Figure 2). The fact that the ability of the side chains to order (or crystallize) depends on the side-chain length is well known for comb-like polymers with a flexible backbone; in general, a minimum length of about 10 to $12 \mathrm{CH}_{2}$ units is required for the side chains to crystallize ${ }^{19}$. Above $100^{\circ} \mathrm{C}$ three endotherms are detected in the first heating run, which are denoted as $T_{m}, T_{\mathrm{n}}$ and $T_{\mathrm{i}}$ respectively. The endotherm at the lowest temperature, $T_{\mathrm{m}}$, is the main-chain melting temperature. At this temperature the layered mesophase $\mathrm{L}_{\mathrm{m}}$ is formed. At a higher temperature $T_{\mathrm{n}}$ the layered ordering that is present in this mesophase is lost and a nematic mesophase $\mathrm{N}$ is formed ${ }^{11}$. The parallel ordering of the main chains that is present in this mesophase finally disappears at the clearing temperature $T_{\mathrm{i}}$. Upon reheating a once molten material (Figure $2 b$ ) the transitions are located at somewhat lower temperatures. This is probably caused by some degradation, as well as undercooling effects. The phase behaviour of PTA6HQ is shown schematically in Figure 5. At room temperature two layered modifications $\mathrm{A}$ and $\mathrm{B}$ can exist ${ }^{10}$. At respectively $T_{\mathrm{m}}$ and $T_{\mathrm{n}}$ the layered and nematic mesophases are formed, while the isotropic melt is reached at $T_{\mathrm{i}}$.

It was reported earlier by Falk et $a .^{11}$ that the transition at $T_{n}$ is very molecular-weight-sensitive; for a polymer with an inherent viscosity of $0.2 \mathrm{dlg}^{-1}$, this transition is shifted to lower temperatures and overlaps with $T_{\mathrm{m}}$. This is illustrated in Figure 6, in which the molecular-weight dependence of the transition temperatures is shown and the data from Falk can be compared with our data points. It can be seen that the temperature range in which the layered mesophase exists broadens with increasing molecular weight. Similar to PTA12HQ a plateau region is reached at an inherent viscosity of $2 \mathrm{dl} \mathrm{g}^{-1}$.

The PTAHQ12 polymer was used to investigate the effect of the place of the substituents on the thermal behaviour. For this polymer the low-temperature disordering $T_{\mathrm{s}}$ of the side chains is located around $100^{\circ} \mathrm{C}$ in the first and second d.s.c. runs (Figure 2). This corresponds to the side-chain disordering temperature of PTA12HQ in modification B. By X-ray diffraction it was

$$
A \text { or } B \stackrel{T_{m}}{\rightleftarrows} L_{m} \stackrel{T_{n}}{\rightleftarrows} N \stackrel{T_{i}}{\rightleftarrows} \mathbf{I}
$$

Figure 5 Scheme of the phase behaviour in PTA6HQ powders, showing the transitions from the two room-temperature modifications $A$ and $B$ to the layered mesophase $L_{m}$, the nematic mesophase $N$ and the isotropic phase I

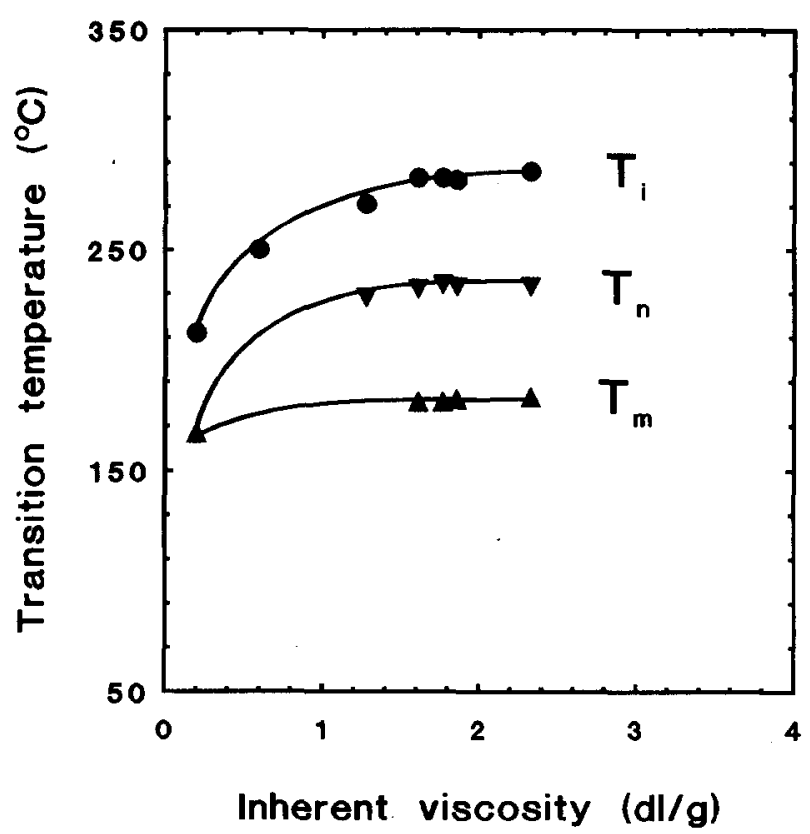

Figure 6 Transition temperatures $T_{m}(\boldsymbol{A}), T_{n}(\boldsymbol{\nabla})$ and $T_{\mathrm{i}}(\boldsymbol{O})$ as functions of the inherent viscosity for PTA6HQ (from first heating runs). Data below $\eta_{\text {inh }}=1.4 \mathrm{dl} \mathrm{g}^{-1}$ were taken from Ballauff ${ }^{7}$ and Falk ${ }^{11}$ 


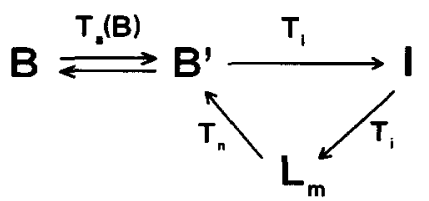

Figure 7 Scheme of the phase behaviour in PTAHQ12 powders. Upon heating modification $B$ the intermediate phase $\mathbf{B}^{\prime}$ is obtained, which transforms to the isotropic melt $I$ at the clearing temperature $T_{i}$. On cooling from the isotropic melt the layered mesophase $\mathrm{L}_{m}$ is passed (monotropic behaviour)

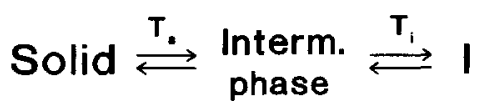

Figure 8 Scheme of the phase behaviour in PTA12HQ12 powders. Upon heating the solid room-temperature phase to above the side-chain melting temperature $T_{\mathrm{s}}$, an intermediate phase is formed, which transforms to the isotropic melt at the clearing temperature $T_{\mathrm{i}}$

indeed found by others that PTAHQ12 is in crystal form $B$ at room temperature ${ }^{6}$. The melting transition of the main chains is located at a higher temperature compared to PTA12HQ and overlaps with the transition to the isotropic phase at $T_{\mathrm{i}}$. In the cooling run, however, $T_{\mathrm{i}}$ and $T_{\mathrm{m}}$ are clearly separated and a liquid-crystalline phase can be detected. This monotropic behaviour was reported earlier by Rodriguez-Parada et al ${ }^{6}$.

In Figure 7 the phase behaviour of PTAHQ12 is shown schematically. The higher main-chain melting temperature as compared to PTA12HQ and the insolubility of this polymer in chloroform suggest a better crystal packing in the case of substitution on the hydroquinone moiety. From the cooling runs it is indeed apparent that the heat of crystallization (when going from $\mathrm{L}_{\mathrm{m}}$ to the intermediate phase $\mathrm{B}^{\prime}$ ) is much higher than in PTA12HQ $\left(\Delta H_{\mathrm{c}} \approx 33 \mathrm{~J} \mathrm{~g}^{-1}\right.$ for PTAHQ12, compared to $\Delta H \approx 8 \mathrm{~J} \mathrm{~g}^{-1}$ for PTA12HQ). This could mean that above $T_{\mathrm{s}}$ the main chains are better ordered in PTAHQ12 compared to PTA12HQ. More information regarding this point is gained from results obtained by RodriguezParada et $a l^{6}$. They showed that the layer spacing of PTAHQ16, in the temperature region between $T_{\mathrm{s}}$ and $T_{\mathrm{m}}$, resembles that of modification B. For PTA16HQ the layer spacing in this temperature region resembles that of modification A. If we combine these results with our own findings (high-temperature $\mathrm{X}$-ray diffraction on PTAHQ12 ${ }^{20}$ ) it seems justifiable to suppose that PTAHQ12 is in a phase resembling phase B between $T_{\mathrm{s}}$ and $T_{m}$. This is why this phase is denoted as $\mathbf{B}^{\prime}$.

In PTA12HQ12, which is substituted on both moieties, the high amount of side chains prevents the formation of a mesophase; no liquid-crystalline behaviour is detected. After disordering of the side chains at about $85^{\circ} \mathrm{C}$ the main-chain structure melts at $190^{\circ} \mathrm{C}$ and an isotropic melt is formed (Figure 2). This is shown schematically in Figure 8.

\section{Rheology}

PTA6HQ $\left(\eta_{\text {inh }}=2.3 \mathrm{dl} \mathrm{g}^{-1}\right)$, PTA12HQ $\left(\eta_{\text {inh }}=2.8 \mathrm{dl}\right.$ $\left.\mathrm{g}^{-1}\right)$, PTAHQ12 $\left(\eta_{\mathrm{inh}}=0.7 \mathrm{dl} \mathrm{g}^{-1}\right)$ and PTA12HQ12 $\left(\eta_{\mathrm{inh}}=1.4 \mathrm{dl} \mathrm{g}^{-1}\right)$ were characterized with a Rheometrics dynamic spectrometer. The complex viscosity $\eta^{*}$ is shown as a function of temperature in Figure 9.

The two polymers that do not exhibit a liquidcrystalline phase upon heating, PTAHQ12 and
PTA12HQ12, shows a decrease in viscosity at the respective transition temperatures to the isotropic melt. These temperatures compare well with the transitions observed by d.s.c. Because of their low molecular weight, the viscosity in the isotropic melt is very low compared to PTA6HQ and PTA12HQ.

From the d.s.c. measurements as well as publications by others ${ }^{9-11}$, we concluded that PTA12HQ shows a layered mesophase between $\sim 170$ and $240^{\circ} \mathrm{C}$. From Figure $9 b$ it can be concluded that the layered mesophase has a viscosity resembling that of the intermediate phase $A^{\prime}$.
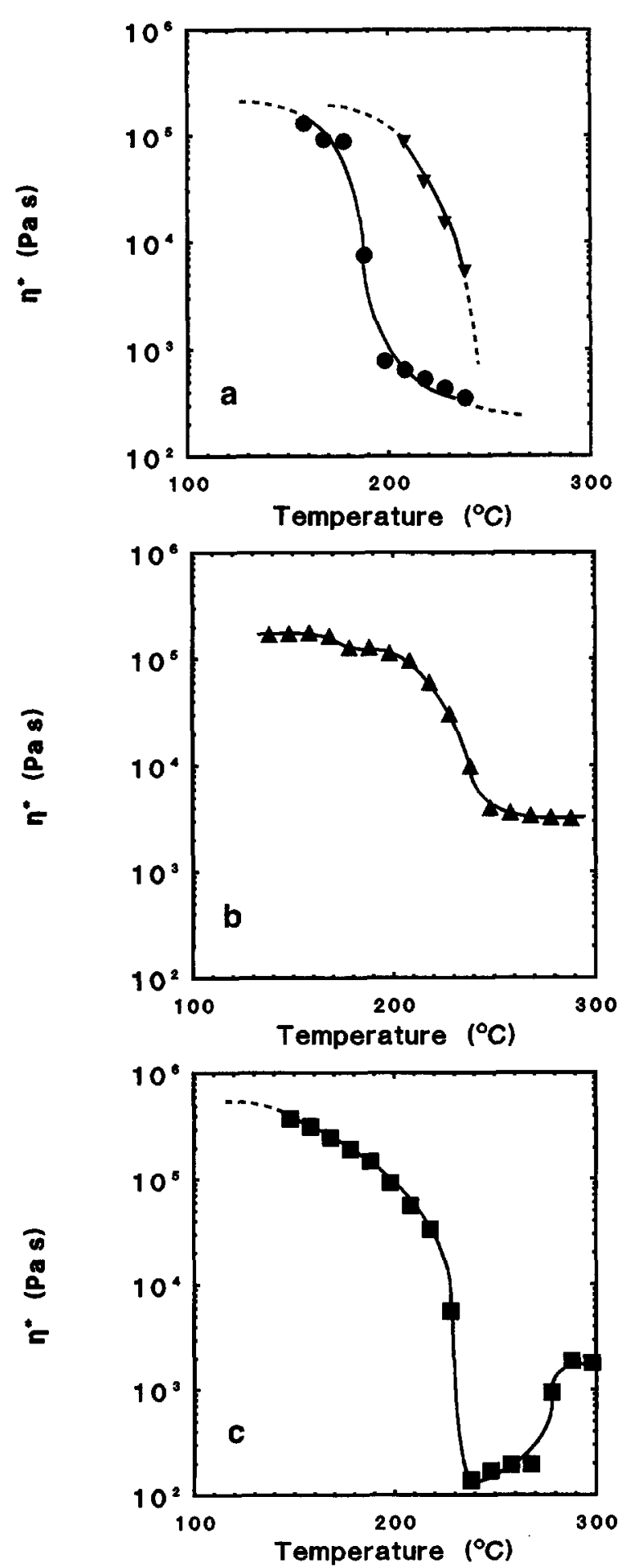

Figure 9 Complex viscosity $\eta^{*}$ at $10 \mathrm{rads}^{-1}$ as a function of temperature: (a) PTAHQ12 ( $)$ and PTA12HQ12 (O); (b) PTA12HQ (A); (c) PTA6HQ (ם) 
For PTA12HQ it can be seen that the viscosity shows a small stepwise decrease on entering the layered mesophase at the main-chain melting temperature $\left(170^{\circ} \mathrm{C}\right)$, followed by a plateau region. At about $210^{\circ} \mathrm{C}$, corresponding to the start of the broad d.s.c. transition to the isotropic melt (Figure 2), the melt viscosity starts to decrease and reaches a new plateau at about $260^{\circ} \mathrm{C}$ (the end of the d.s.c. endotherm).

Though rheological data on PTA6HQ $\left([\eta]=0.48 \mathrm{dl} \mathrm{g}^{-1}\right)$ have been published recently by Schrauwen et al. ${ }^{12}$, the higher molecular weight of the polymer (which was shown to have a significant effect on the transition temperatures) used by us makes it useful to present our rheological data. The viscosity-temperature curve of PTA6HQ, shown in Figure $9 c$, reveals that the plateau region for the layered mesophase cannot be discerned as clearly as for PTA12HQ. Already at $200^{\circ} \mathrm{C}$ the viscosity starts to decrease, and at about $230^{\circ} \mathrm{C}$, corresponding to the transition to the nematic melt as found by d.s.c., a drastic decrease in the melt viscosity is observed. Such a very low melt viscosity, followed by an increase in viscosity on entering the isotropic phase, is typical for a nematic melt $^{21}$ and is also observed for lyotropic polymers ${ }^{22}$. Thus the assignment of this phase by Falk ${ }^{11}$ is affirmed by the present rheological measurements. In the isotropic phase the viscosities of PTA6HQ and PTA12HQ are of the same order of magnitude.

To illustrate the rheological behaviour in the layered and nematic mesophases, the storage and loss moduli $G^{\prime}$ and $G^{\prime \prime}$ of PTA6HQ are shown as a function of frequency in Figure 10. Data at four different temperatures, corresponding to the four different phases that can exist in this polymer, are shown. In the solid phase as well as in the layered mesophase an elasticity-dominated state exists; the storage modulus exceeds the loss modulus. In the nematic mesophase a viscosity-dominated state is found $\left(G^{\prime \prime}>G^{\prime}\right)$, while $G^{\prime}$ and $G^{\prime \prime}$ almost equal each other in the isotropic phase. This leads to the conclusion that

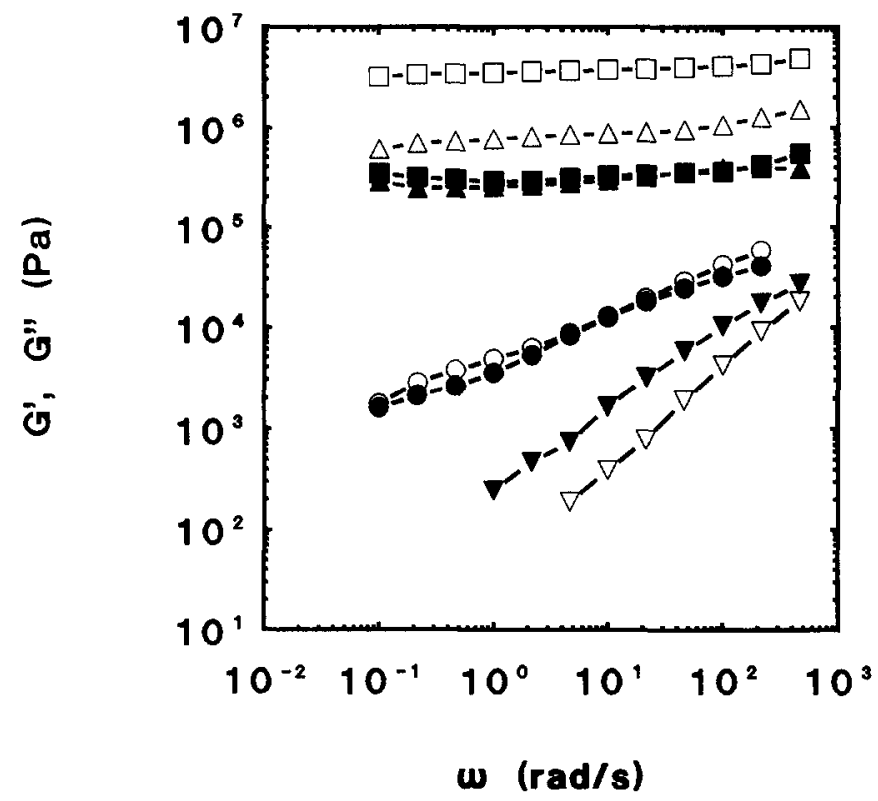

Figure 10 Storage and loss moduli of PTA6HQ in the solid phase $\left(\square, \square, 150^{\circ} \mathrm{C}\right)$, the layered mesophase $\left(\triangle, \Delta, 200^{\circ} \mathrm{C}\right)$, the nematic mesophase $\left(\nabla, \nabla, 250^{\circ} \mathrm{C}\right)$ and the isotropic phase $\left(\mathrm{O}, 295^{\circ} \mathrm{C}\right)$. Open symbols refer to the storge modulus $G^{\prime}$, closed symbols to the loss modulus $G^{\prime \prime}$ the layered mesophase resembles a solid phase, while the nematic mesophase behaves like a liquid.

\section{CONCLUSIONS}

The phase behaviour of substituted PPTs was shown to be strongly dependent on the position and length of substituents. Only the two polymers with substituents on the terephthalate moiety show stable liquid-crystalline phases.

For both PTA6HQ and PTA12HQ the transition temperatures are strongly dependent on the molecular weight below an inherent viscosity of $1.5 \mathrm{dl} \mathrm{g}^{-1}$. Above an inherent viscosity of $2 \mathrm{dl} \mathrm{g}^{-1}$ this dependence levels off.

From rheological measurements it is concluded that the layered mesophase, shown by PTA6HQ and PTA12HQ, behaves more like a solid than a liquid. The nematic mesophase shown by PTA6HQ has a very low melt viscosity and, similar to other nematic polymers, the viscosity of this polymer increases at the transition from nematic to isotropic melt.

\section{ACKNOWLEDGEMENTS}

We are indebted to Dr Ir J. A. H. M. Buijs and Dr G. J. Vroege for stimulating discussions and carefully reading the manuscript. We would also like to thank Professor Dr M. Ballauff for his continuing interest and helpful suggestions throughout the course of this work. The performance of a great deal of the synthetic work by Dr A. H. A. Tinnemans and coworkers is greatly appreciated. Financial support from the Dutch Ministry of Economic Affairs (IOP-PCBP 302) and DSM is gratefully acknowledged.

\section{REFERENCES}

1 Northolt, M. G. and Sikkema, D. J. Adv. Polym. Sci. 1990,98, 118 2 Ballauff, M. Angew. Chem. 1989, 101, 261

3 Mühlebach, A., Economy, J., Johnson, R. D., Karis, T. and Lyerla, J. Macromolecules 1990, 23, 1803

4 Cheng, S. Z. D., Janimak, J. J., Zhang, A. and Zhou, Z Macromolecules 1989, 22, 4240

5 Kaito, A., Kyotani, M. and Nakayama, K. Macromolecules 1990 23, 1035

6 Rodriguez-Parada, J. M., Duran, R. and Wegner, G. Macromolecules 1989, 22, 2507

7 Ballauff, M. Makromol. Chem., Rapid Commun. 1986, 7, 407

8 Ballauff, M. Liq. Cryst. 1987, 2, 519

9 Ballauff, M. and Schmidt, G. F. Makromol. Chem., Rapid Commun. 1987, 8, 93

10 Ballauff, M. and Schmidt, G. F. Mol. Cryst. Liq. Cryst. 1987 , 147, 163

11 Falk, U. and Spiess, H. W. Makromol. Chem., Rapid Commun. $1989,10,149$

12 Schrauwen, C., Pakula, T. and Wegner, G. Makromol. Chem. $1992,193,11$

13 Ramage, G. R. and Stead, C. V. J. Chem. Soc. 1953, 1393

14 Ringsdorf, H., Tschirner, P., Hermann-Schönherr, $O$. and Wendorff, J. H. Makromol. Chem. 1987, 188, 1431

15 Baldwin Frech, C., Adam, A., Falk, U., Boeffel, C. and Spiess, H. W. New Polym. Mater. 1990, 2 (3), 267

Damman, S. B. and Vroege, G. J. Polymer in press

Majnusz, J., Catala, J. M. and Lenz, R. W. Eur. Polym. J. 1983 19, 1043

18 Majnusz, J. Mol. Cryst. Liq. Cryst. 1990, 193, 161

19 Platé, N. A. and Shibaev, V. P. J. Polym. Sci., Macromol. Rev. $1974,8,117$

20 Damman, S. B. and Mercx, F. P. M. J. Polym. Sci., Polym. Phys. $E d n$. in press

21 Wissbrun, K. F. and Griffin, A. C. J. Polym. Sci., Polym. Phys. Edn. 1982, 20, 1835

22 Wissbrun, K. F. J. Rheol. 1981, 25 (6), 619 